\title{
Stability Monitoring and Deformation Laws of the Yuanjue Cave in the Influence Zone of the Unloading Zone
}

\author{
Zhigang Meng $\mathbb{D}^{1,2,3}$ Fengnian Wang $\mathbb{D}^{1,4}$ Gan Qi, ${ }^{5}$ Xuebin Cui $\mathbb{D}^{1,4}$ and Juan Ma \\ ${ }^{1}$ State Key Laboratory for Geomechanics and Deep Underground Engineering, China University of Mining and Technology, \\ Beijing 100083, China \\ ${ }^{2}$ Liaoning Research Institute for Nonferrous Metals, Shenyang 110000, China \\ ${ }^{3}$ Dazu Rock Carving Research Institute, Chongqing 402360, China \\ ${ }^{4}$ School of Mechanics and Civil Engineering, China University of Mining and Technology, Beijing 100083, China \\ ${ }^{5}$ China Geological Environment Monitoring Institute, No. 20, Dahui Temple, Haidian District, Beijing 100081, China
}

Correspondence should be addressed to Fengnian Wang; wangfn_bj@163.com

Received 10 December 2020; Revised 10 January 2021; Accepted 15 January 2021; Published 8 February 2021

Academic Editor: Feng Xiong

Copyright (c) 2021 Zhigang Meng et al. This is an open access article distributed under the Creative Commons Attribution License, which permits unrestricted use, distribution, and reproduction in any medium, provided the original work is properly cited.

\begin{abstract}
As a representative of cliff-like stone cultural relics, caves are carved on natural mountains and cliffs, which overlap with the influence zone of the geological unloading zone. Cracks in the unloading zone lead to stability issues, including falling blocks, collapse, water seepage, and deformation. This article analyzes the stability of the roof facing the Yuanjue Cave, the cultural heritage site of Dazu Rock Carvings. We systematically analyzed the characteristics of the Yuanjue Cave and established a method to monitor cave stability based on the framework of the protection system. As shown through in-field practice, the monitoring method showed good modularization, construction, and spatial expansion performance in narrow spaces. Taking fracture displacement, roof subsidence, roof denudation rates, and roof pressure as monitoring elements, the method showed high precision over a short timeframe. The deformation law of the surrounding rock mass was also obtained through coupling the analysis of multisource monitoring data in the Yuanjue Cave. The method could integrate protection and monitoring systems, permitting preservation of the Yuanjue Cave and its cultural relics, providing a useful reference for similar cases.
\end{abstract}

\section{Introduction}

The cave temple, as a representative of the cliff-like stone cultural relics, is an architectural form that was introduced to China from India with Buddhism. It is based on Buddhism, spreading West to East and South along the Silk Route, and is widely distributed [1-3]. Following the footsteps of Buddhism, Sichuan, Chongqing, and other regions continued the art form of cave temples into the Song Dynasty. The Dazu Rock Carvings are one of the rare remains of Confucianism, Buddhism, and Taoism [4]. Grotto temples are directly carved on the natural mountains and cliffs, forming part of these cultural relics. However, as the mountain cliff is typically situated in the developing region of the unloading zone, the grotto itself is typically influenced by cracks in the unloading zone and is prone to collapse, overturning, and landslide due to the action of internal and external forces. This threatens the safety of cultural relics in the grotto temple [5-9].

The cultural relic protection of Grotto temples in China has gradually shifted from rescue protection to both rescue and preventive protection $[10,11]$. Intense research has been performed to establish proactive protection, monitoring, and early warning systems in grotto temples [12-17]. For example, Wang and colleagues used instruments such as joint gauges, inclinometers, multipoint displacement meters, thermometers, and hygrometers to monitor the stability of Yungang Grottoes surrounding the rock mass inclination, crack development, and cracking and spalling of the rock mass surface. The use of bolt technology to strengthen the roof of Cave 14 was also performed following the early warning of rock mass instability and the need for roof reinforcement [18]. Through the monitoring and analysis of temperature and humidity, ultraviolet light, carbon dioxide, sulfur 


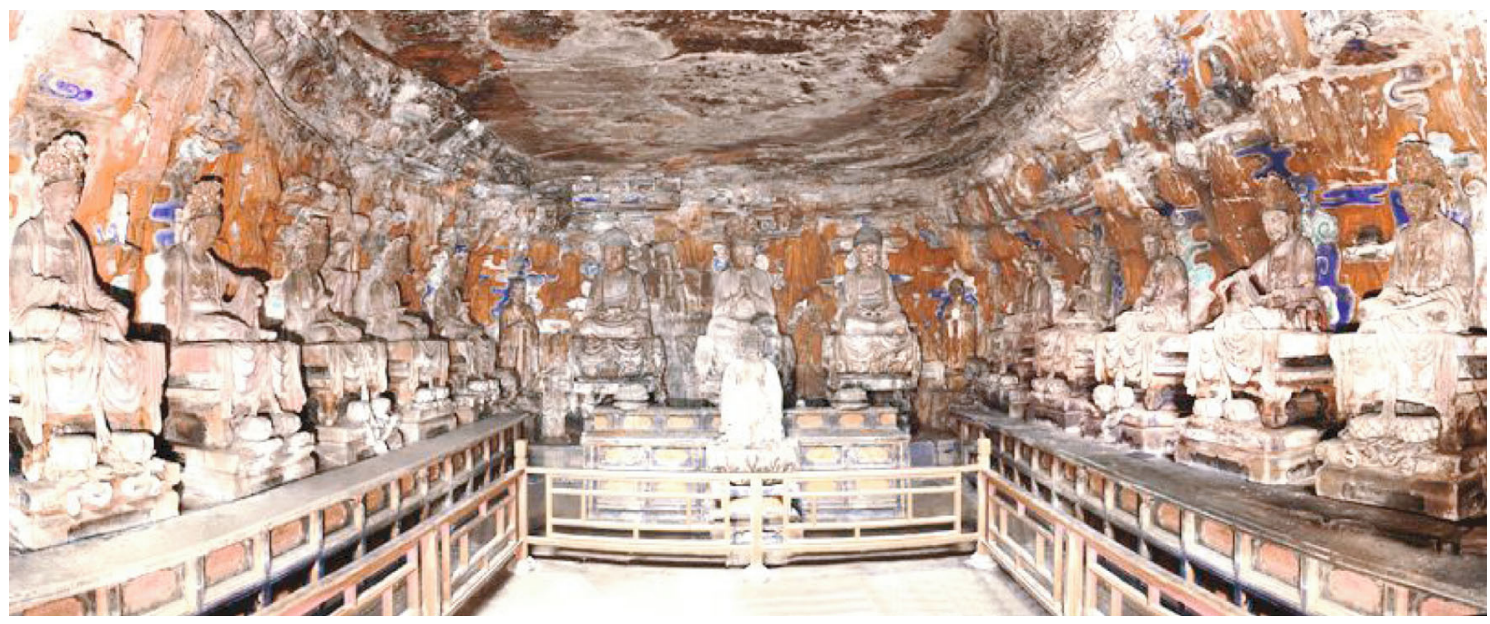

Figure 1: Shape of the internal Buddhist niches.

dioxide, and other factors in the Sanyou cave cliff carving area, Gao and colleagues used the roof method to strengthen Cave 3 [19]. Brandi et al. considered the need to protect natural caves and sustainable mining operations and proposed a remote geotechnical monitoring method to predict cave instability [20].

However, deficiencies in the monitoring and protection of grotto temples persists, including the mutual dispersion of monitoring data, the decoupling of protective structures and monitoring, the lag in studies of the deformation law of the grotto rock mass, and the emphasis on the surface of cultural relics and environmental monitoring [21-23].

Dazu Rock Carvings are known as "the last monuments in the history of human grotto art" and represent the highest level of world grotto art in the 9th to 13 th centuries AD. The Yuanjue Cave is representative of these monuments. However, under the long-term action of natural forces and human factors, fracture development accelerated weathering, rock denudation, and roof instability have appeared in the rock mass adjacent to the cave [24]. In response to the erosion of the base rock of the Yuanjue Cave, a reinforcement work has been performed to alleviate danger. However, the stability of the roof of the Yuanjue Cave is unknown and requires urgent protection work. For preventive protection, an extensible flexible jacking system was designed. The fiber Bragg grating sensors are widely used in structural health monitoring due to their anti-interference, corrosion resistance, and high precision $[25,26]$. In this study, a monitoring system for roof deformation and pressure within the Yuanjue Cave, coupled to rock mass deformation in adjacent areas, surface weathering rates, and the deformation of close fissures has been established. The preliminary construction of this system for the protection of the roof of the Yuanjue Cave and the adjacent rock masses provides a useful reference for the protection of similar grottoes.

\section{Regional Geological Conditions of the Yuanjue Cave}

2.1. Artistic Value of the Yuanjue Cave. Dazu Stone carvings are located in the Northwest of Chongqing city. They were carved in the Tang Dynasty and flourished in the Song Dynasty. Notable examples include Beishan, Baoding Mountain, Nanshan Mountain, Shizhuan Mountain, and Shimen Mountain. As a world cultural heritage site, the Dazu Stone carvings have high historical, artistic, scientific, social, and cultural values. As a representative of the Dazu Stone carvings, the Yuanjue Cave has unique craftsmanship that integrates decoration, drainage, and lighting, fully demonstrating the creative ability of ancient carving masters.

2.2. Geometric Features of Circular Holes. The Yuanjue Cave is 12 meters deep, 9 meters wide, and 6 meters high. It is the largest cave statue in the Big Buddha Bay and is located on the upright cliff face of the south cliff of the Big Buddha Bay Chonggou, Longtangou Branch, Baoding Town. It is almost East-West and formed by erosion from East to West. The overall shape is " $U$," with a length of more than 340 meters and a width of more than 90 meters. Elevation at the bottom of the valley is approximately 462-473 meters, and the height of the cliff wall height is generally greater than 6 meters. There is a roaring stone lion at the entrance of the cave. The front wall of the cave is engraved with "three bodies" (Dharmakaya, Yingshen, and Samshen). There are twelve round sensations on both sides of the cave, six on the left and six with a pedestal below. The six bases are connected, and the entrance tunnel is approximately 6.5 meters in length. The maximum height in the Yuanjue Cave is 6.02 meters, 9.55 meters wide, and 12.13 meters deep. Figure 1 shows the shape of the Buddhist niches inside the Yuanjue Cave.

\section{Disease Development in the Yuanjue Cave}

3.1. Cracks across the Hole. The surrounding rock strata of the Yuanjue Cave is formed from the red sandstone of the Sichuan Basin, belonging to the sedimentary environment of fluvial and lacustrine facies. The strata are mainly horizontal fine-grained sandstone with interbedded mudstone. Thin sandstone layers with more flaky mica are present within some areas. The lithology of the strata varies and interbedded sandstone and mudstone are prominent. The sedimentary environment of the rock properties is complex and formed 


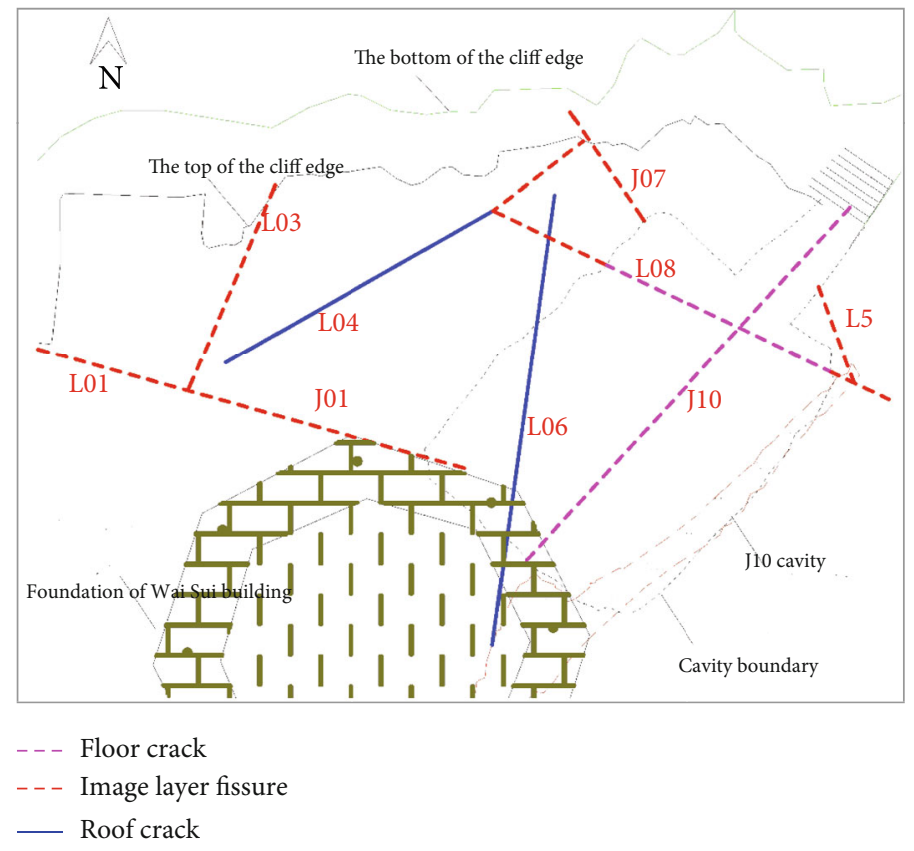

FIgURE 2: Distribution map of cracks around the Yuanjue Cave.

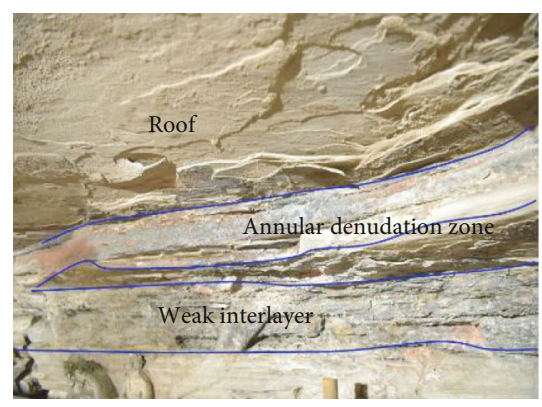

(a) Section of annular denudation zone

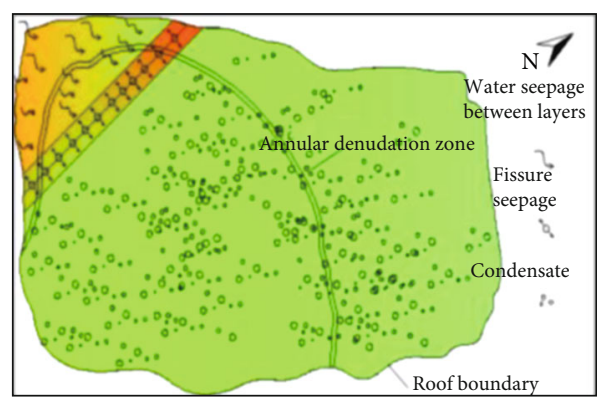

(b) Distribution of roof water damage types

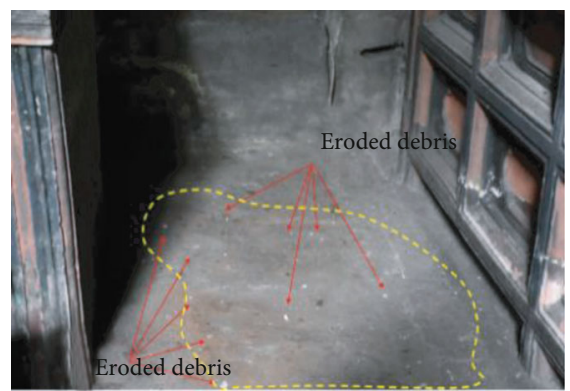

(c) Top plate L6 crack denudation groove

Figure 3: Water damage and surface erosion on the roof of the Yuanjue Cave.

from the unique natural geographical landscape and lithology, with good resistance to weathering. The rock has formed a prominent canopy structure, with the weaker rock forming the Buddha bay imaging layer, on which the carved statues are protected by the upper canopy, avoiding direct wind and rain erosion.

According to the survey, 13 fractures developed in the surrounding rock mass of the Yuanjue Cave, with each fracture dislocated or pinched out in the soft rock stratum, result- ing in an altered appearance of major fractures in the adjacent rock stratum. Amongst them, six main fractures are present in the surrounding rock mass directly cut by the Yuanjue Cave, namely, J-01, J-07, J-10, L05, L06, and L08. Of these, only L6 fractures developed in the roof layer, with five fractures, namely, J01, J07, J10, L05, and L08, being exposed in the carved stone layer and floor rock mass of the circular cave. The distribution characteristics of the main fractures in the different layers are shown in Figure 2. The 


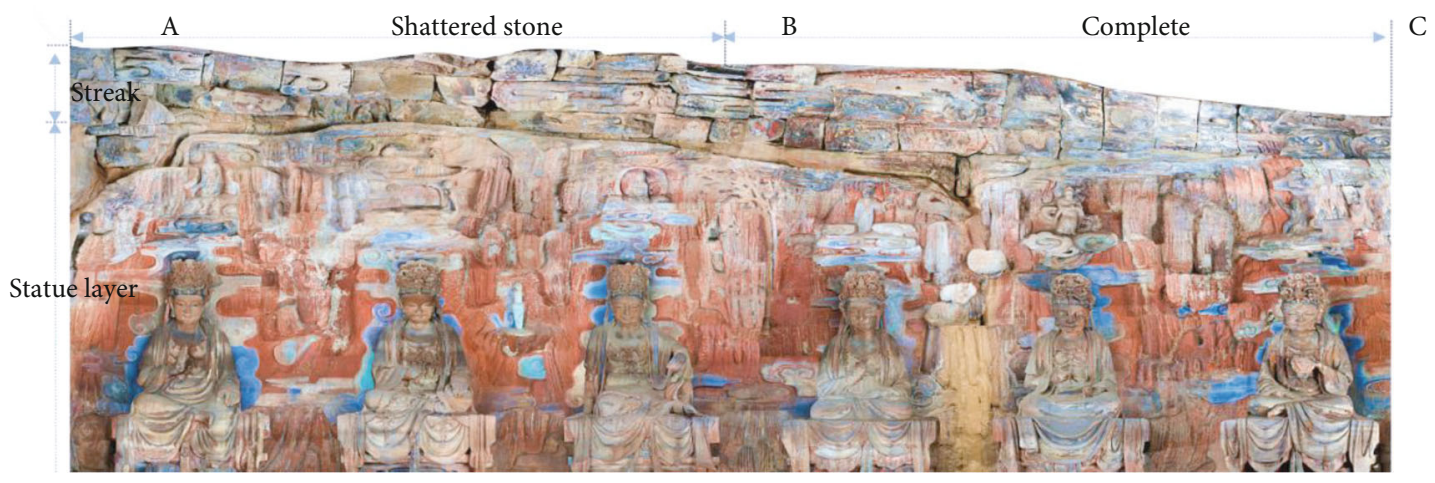

(a) The position of the Buddha niche in the cave is shaped and filled with strips of stone

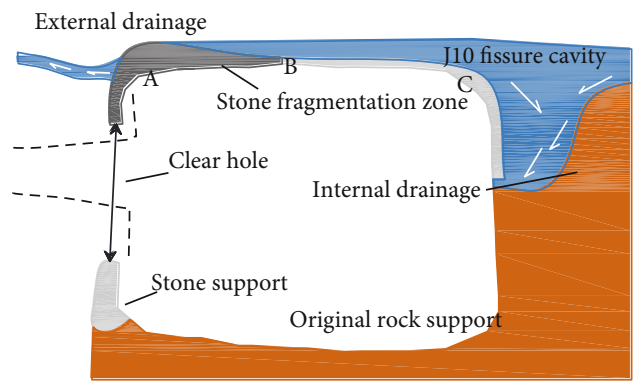

(b) Round hole roof support condition

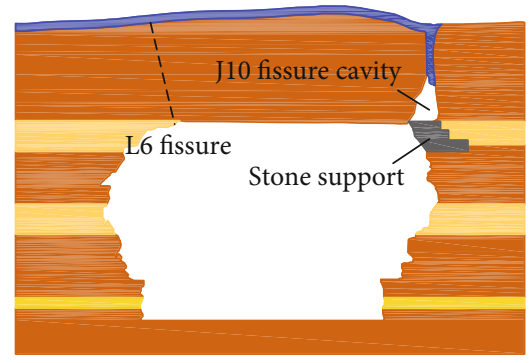

(c) The rock mass structure of Yuanjue Cave cross section

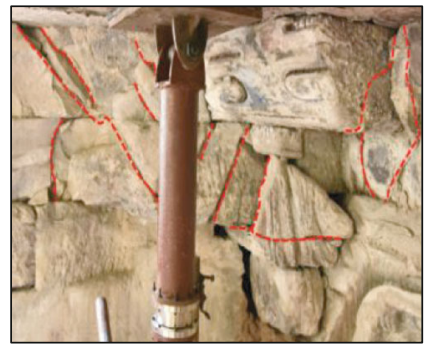

(d) Crushing condition of supporting strip

Figure 4: Preservation state of the roof support of the Yuanjue Cave.

widely distributed fractures cut the rock mass around the Yuanjue Cave, seriously influencing the stability of the body and surrounding rock of the Cave.

3.2. Roof Seepage and Weathering Denudation. Roof leakage of the Yuanjue Cave can be divided into two types according to the mode of action. The first type is directly infiltrated by water seepage from outside the cave through bedding or cracks, leading to the gradual warping and hollow drum of the original weak layer of the roof, with eventual spalling. This type of erosion is harmful, with denudation occurring along the cracks directly to both sides. The second type is eroded by condensation water in the cave, leading to increased surface humidity of the roof in the cave, exacerbating roof warping, empty drum, and finally peeling. Fracture seepage and rock dry and wet cycle have important influence on the stability of rock mass structure [27-29]. Water seepage on the roof of the Yuanjue Cave is concentrated in the Southwest corner. There is a weak interlayer in the vertical direction between the roof and image layer, where a fine plant root system is present. The Southwest corner of the roof harbors the L6 crack, with large volumes of water con- centrated on both sides. The weathering and denudation depth of the roof along the $\mathrm{L} 6$ crack reaches $\sim 5 \mathrm{~cm}$. See Figure 3(b) for water seepage in the roof of the Yuanjue Cave.

Through detailed investigations of roof weathering and denudation disease, more than 41 areas of roof cavitation, cracking, and warping have been identified. The roof is dominated by layered weathering and denudation, forming a series of diseases empty drums, cracking, and warping along with bedding, leading to the formation of denudation particles (Figure 3(c)). The most significant feature is the existence of a thick layered circular denudation step on the roof of the circular cavity. The partial fracture of the denudation step presents an irregular vertical oblique shape, with a broken section and vertical included an angle close to $60-70^{\circ}$. The visible section in the annular fracture zone hole is 10.2 meters. The morphology of the denudation fracture is shown in Figure 3(a). Weathering and denudation of the roof have gradually progressed to the center in the vertical direction and are diffused in the near-circular core of the horizontal direction. It is speculated that the roof will eventually form a "dome" denudation form. 


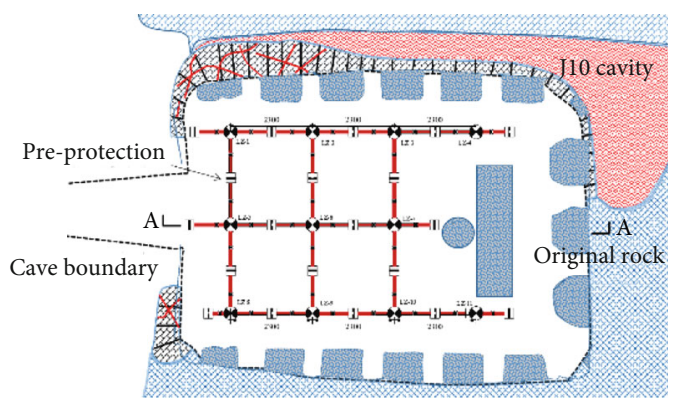

(a) Floor plan of supporting roof (stress monitoring) system

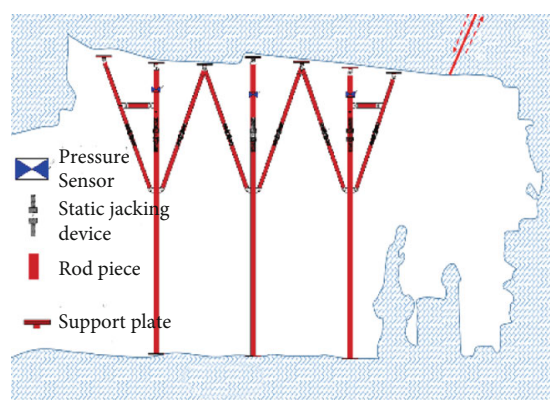

(b) Partial elevation of roof support system

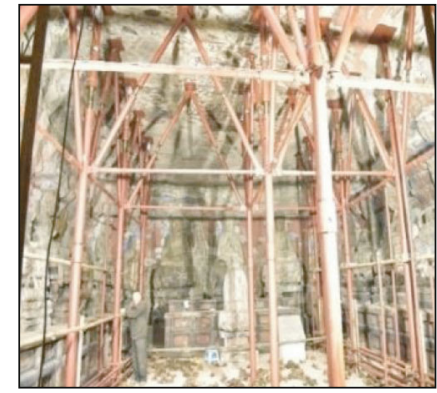

(c) Support system entity diagram

Figure 5: Yuanjue Cave roof preprotection system.

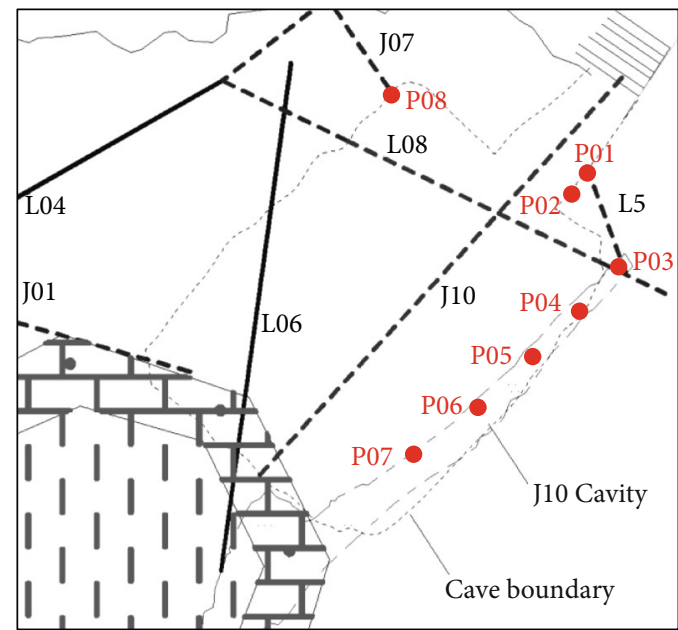

(a) Fissure displacement monitoring points

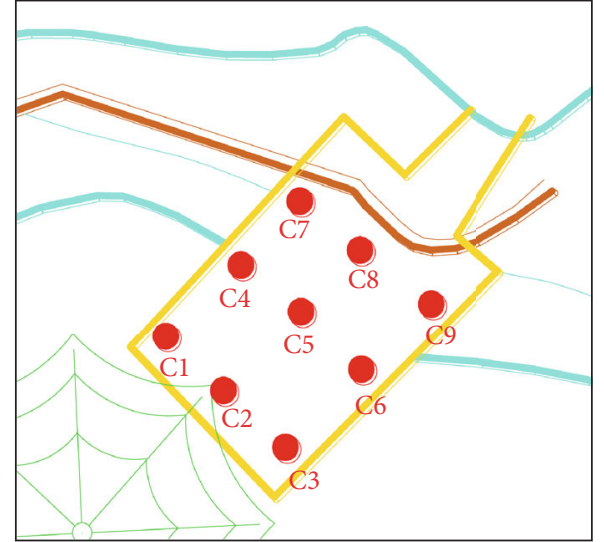

(b) Leveling settlement monitoring points

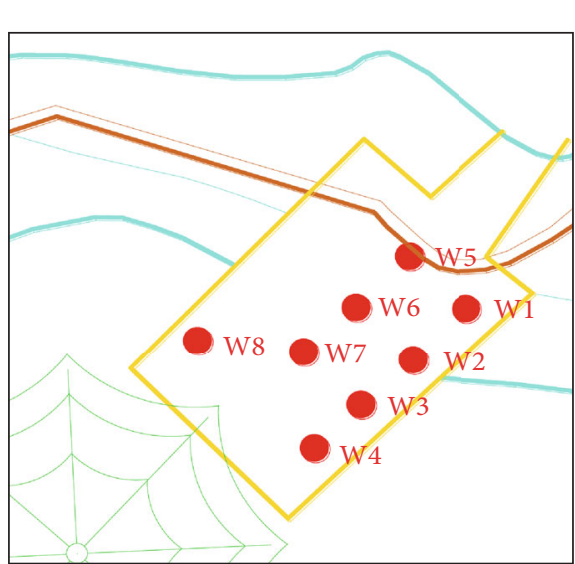

(c) Settling pressure monitoring points

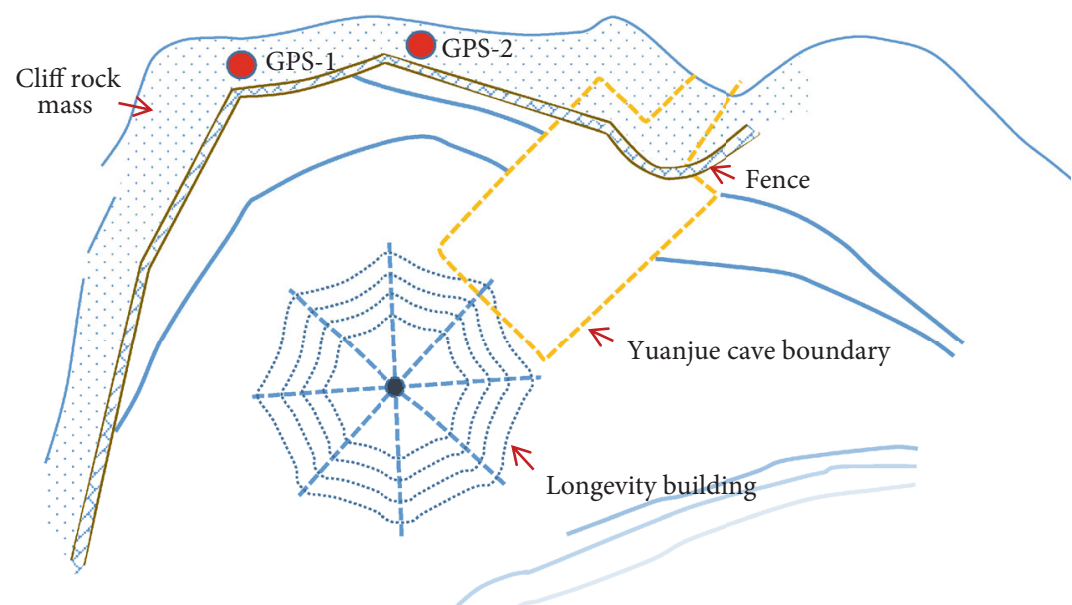

(d) Adjacent to the rock mass displacement monitoring points

FIGURE 6: Layout of the monitoring points.

3.3. Cracking in the Roof Support Strip. At the initial stage of the Yuanjue Cave, the East side of the roof is supported by the filling strip stone (Figure 4). After more than 700 years, the state of the roof support body has undergone a series of changes. The heterogeneous rock mass is prone to creep fail- ure of different degrees in a natural environment [30-32]. Deterioration of the filling zone in the Northeast corner of the cavity is obvious, and large levels of fracturing and crushing have occurred in the front filling area. Through field investigations, a large number of compression and direct 


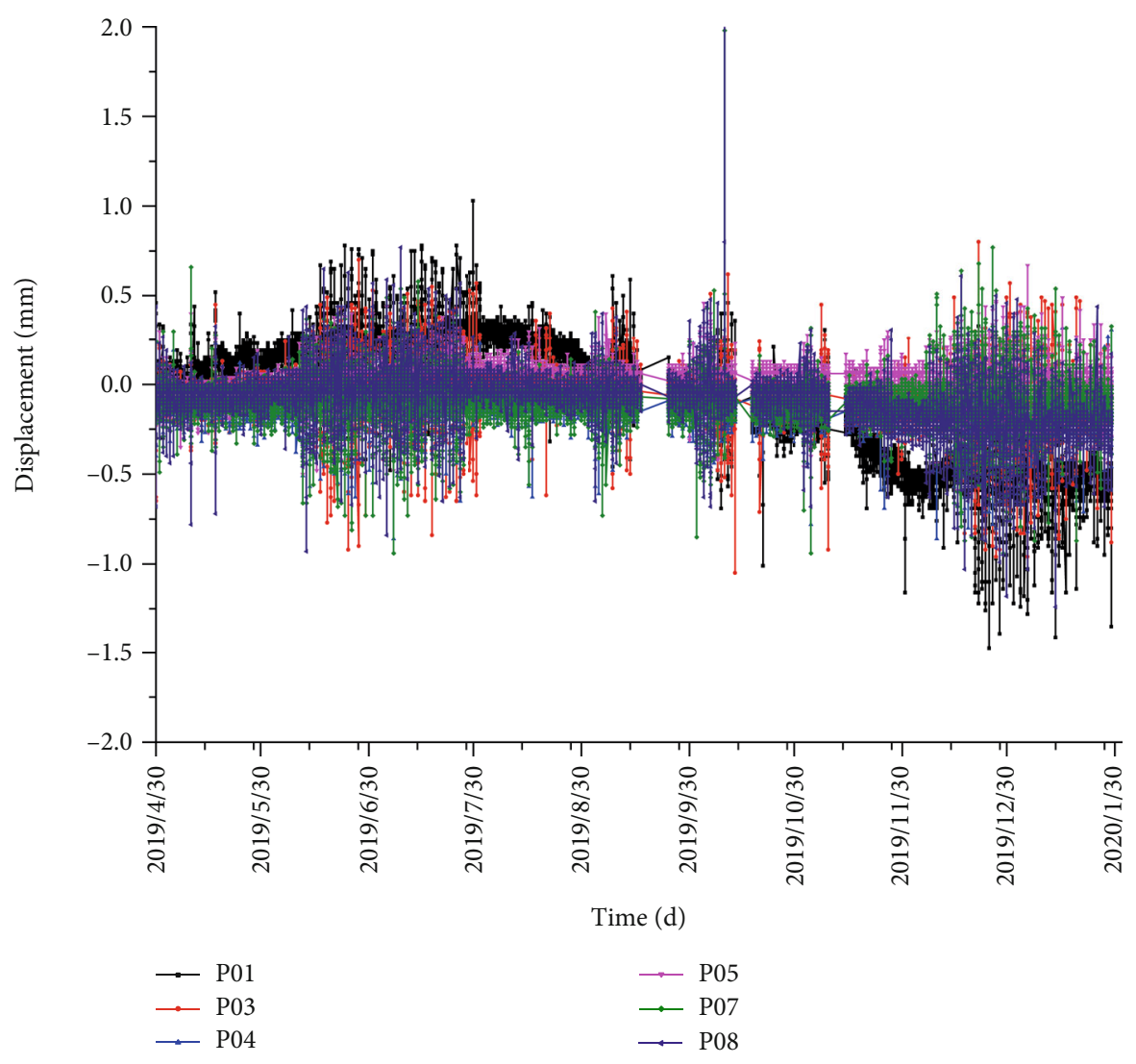

Figure 7: Rock fissure displacement monitoring curve.

shear cracks have occurred in the filled strip stone, with the main plane positions distributed in the East side of the through-light hole and the central area of the Eastern wall, as shown in Figure 4(a).

Fracture of the stripped stone will seriously affect the stability of the dome plate. The strip stone will lose its original compressive properties after fracturing, and its supporting capacity will decrease. At the same time, the upper roof supported by the striped rock was compressed following fracture and sank, forming an uneven settlement on one side of the roof and secondary L6 cracks, as shown in Figure 4(c).

To summarize, the weathering and denudation of the Yuanjue Cave are serious. Fractures have now developed in the surrounding rock, roof joints, and filled bars, seriously affecting the stability and safety of the cave. Urgent stability monitoring of the circular holes is now required to develop a monitoring and early warning system that can evaluate the stability of circular holes.

\section{Construction of the Yuanjue Cave Plate Prevention and Protection System}

4.1. Necessity of Preventive Protection. The Yuanjue Cave has undergone a historical retention process since its excavation. The stability of the roof of the cave has gradually declined from its initial state of stability under various natural and man-made forces, to breaking of the original rock boundary and the supporting rock. This evolutionary development is closely related to the environment, stratum lithology, cave shape, and grotto rock structure [33-35].

Traditional grotto rock mass reinforcement strategies combine analysis and evaluation methods with reinforcement techniques, slope engineering, and underground water conservancy engineering $[36,37]$. These methods have the disadvantage of large disturbances and poor coordination when applied to the protection of grotto cultural relics.

Following evaluation, the total weight of the suspended area of the independent roof block of the Yuanjue Cave was approximately 600 tons. The roof rock mass is brittle with a span of 9 meters and an average thickness of only 2.5 meters. Preventive protection of the Yuanjue Cave is therefore required, but the necessity of process monitoring should be fully considered.

4.2. Preventive Protection Methods. Given the large fluctuations in the inner surface of the roof, the narrow site, the large number of cultural relics in the work area, and the sensitivity of the roof to stress tolerance, a static roof protection system was designed and developed. The system is composed of standard components with strong expansion capabilities. The system uses layered installation, point-by-point lifting, static coupling, monitoring, and supporting links to ensure the safety and stability of the roof of the Yuanjue Cave during the survey and design stage.

The static roof support system is mainly composed of a column and a supporting static adjustment system. Upon 


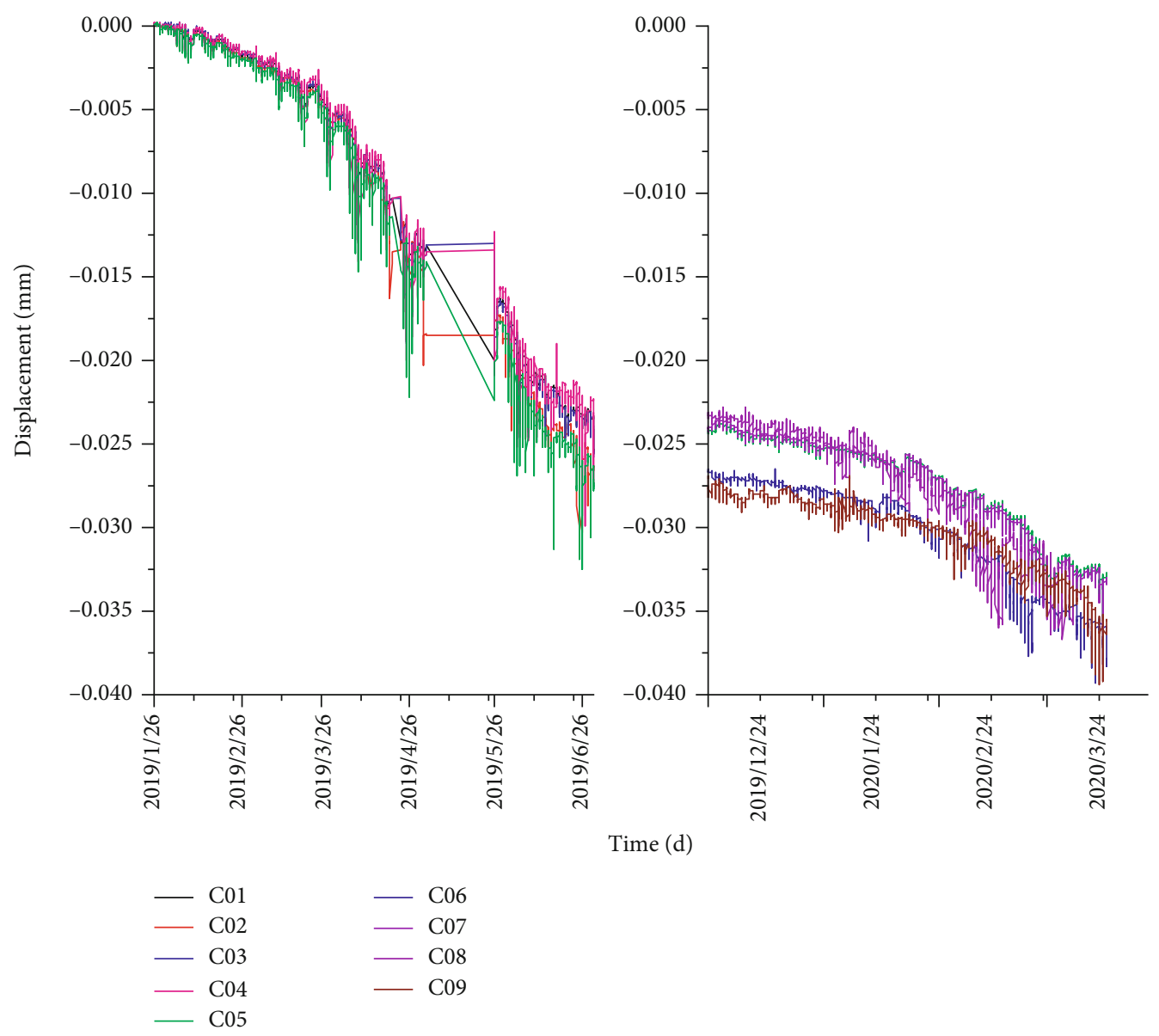

Figure 8: Roof settlement monitoring curve.

consideration of the gravity distribution of the roof, 3 rows of columns are present in the East-West direction of the cave. From left to right, there are 4,3 , and 4 columns. The specific layout is shown in Figure 5(a). The diagonal braces are arranged between the vertical piles, and the diagonal braces between the columns are connected by hinged plates. There are 17 sets of diagonal braces, and the side span diagonal braces are reinforced with steel tie rods to form a supporting system. The layout of the support system is shown in Figure 5(a). The structure of the vertical link is shown in Figure 5(b).

Due to the differences in the elevation distribution of the lower surface of the roof, static jacking devices must be designed at each support node of the system to meet the initial support requirements of the roof. The maximum static jacking stroke can reach $50 \mathrm{~cm}$. Static preload compression is controlled by combining the pressure monitoring sensors. The preload pressure must not exceed $500 \mathrm{~N}$.

The supporting area is supported by square steel plates. To ensure an even fitting with the roof sandstone, a coupling contact layer was set between the roof and steel plate. The contact layer was divided into an isolation layer, an epoxy coupling layer, and an elastic cushion layer. The isolation layer ensures that the surface of the rock body is free from contamination. The epoxy coupling layer shows high plasticity prior to hardening, which can completely contact the uneven roof surface. After hardening, the epoxy layer forms a high-strength rigid body to achieve a uniform roof pressure. The lower area of the epoxy coupling layer contacts the elastic cushion through the antifouling diaphragm. The elastic cushion has a thickness of $10 \mathrm{~mm}$, a maximum linear elastic compression of $4 \mathrm{~mm}$, and an unconfined compression modulus composed of rubber with good elastic properties and antiaging properties.

\section{Construction of the Multisource Intelligent Monitoring System and Analysis of the Monitoring Results}

Through preliminary investigations, the spatial shape, disease status, and boundary conditions of the roof rock mass of the Yuanjue Cave have gradually become clear. The deterioration of the roof rock mass has also gradually been defined. However, the laws of deformation development in the roof rock mass of the Yuanjue Cave over time and space remain unclear. It was necessary to establish a long-term monitoring system to prove these laws. According to the different stress and deformation characteristics of the circular roof plate and surrounding rock, a range of monitoring systems were established, including crack displacement monitoring, roof horizontal settlement monitoring, laser 


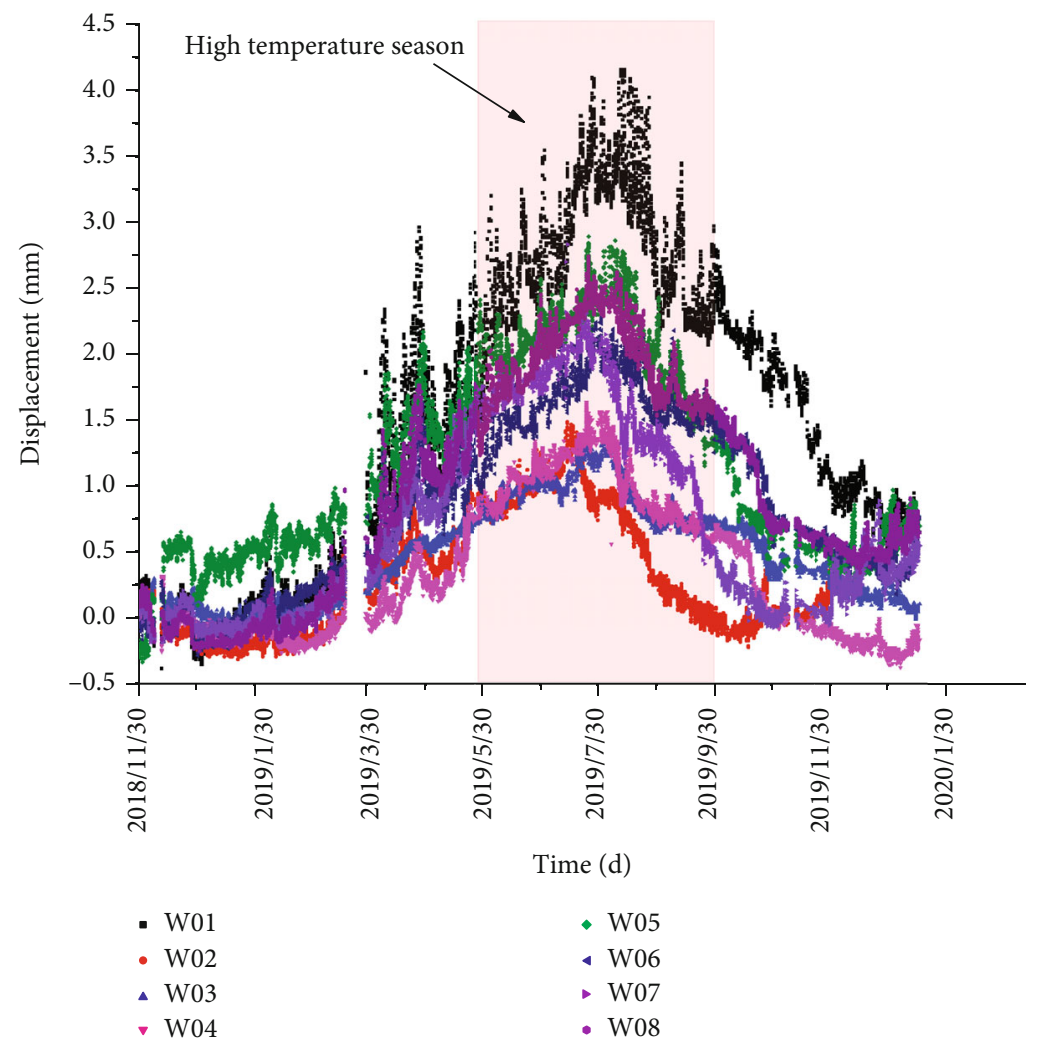

Figure 9: Laser monitoring curve of the ablation rate.

denudation monitoring, roof settlement pressure monitoring, and GNSS deformation monitoring of the cliff and surrounding rock mass.

\subsection{Monitoring Point Locations}

5.1.1. Points of Fissure Displacement Monitoring. Displacement monitoring points were arranged around the fissure in the cutting hole. A total of 8 locations were monitored with an accuracy of $0.1 \mathrm{~mm}$. Through the analysis of the fissures, displacements of J-10, J-01, J-07, and L5 were all (direct or indirectly) affected by the deformation of the roof and surrounding rock. The layout is shown in Figure 6(a).

5.1.2. Points of Roof Level Settlement Monitoring. Settlement monitoring is mainly arranged on the upper surface of the circular roof plate, using the leveling monitoring method. A total of 9 observation points of the roof leveling settlement were arranged, with a monitoring accuracy of $0.1 \mathrm{~mm}$. The installation of the site layout is shown in Figure 6(b).

5.1.3. Points of Ablation Rate Monitoring. Using highprecision laser sensors, long-term monitoring of the ablation speed was performed at a fixed point on the top plate. A total of 8 measuring points were arranged, with a monitoring accuracy reaching $0.05 \mathrm{~mm}$. The monitoring equipment was coinstalled with the supporting system. The site layout is shown in Figure 6(c).

5.1.4. Cliff Deformation Monitoring. The roof stability of the Yuanjue Cave is directly related to the deformation of the adjacent rock mass. Therefore, two GNSS displacement monitoring points were arranged adjacent to the rock mass outside the Yuanjue Cave in February 2019. The GPS-2 monitoring point was located at the corner of the cliff. The GPS-1 monitoring point was located between the corner of the cliff and the Yuanjue Cave. The detailed layout and location are shown in Figure 6(d).

\subsection{Analysis of the Monitoring Results}

5.2.1. Fissure Displacement. The monitoring data of the fissure displacement sensors were used for observation and warning via the Dazu Rock Carving Early Warning Platform (DRCEWP). The monitoring accuracy was $0.1 \mathrm{~mm}$. Monitoring data were collected from April 2019 to February 2020 (Figure 7). Amongst the 8 monitored data points, points P02 and P06 failed to provide valid information. The results suggest that the monitoring data fluctuate within a narrow range around the 0 axes, with a fluctuation range within $\pm 1 \mathrm{~mm}$. The fluctuation of the small displacement may be related to the cave temperature, but the fissures show relative stability.

5.2.2. Roof Level Settlement. Monitoring of the roof surface settlement was initiated on January 26, 2019, with a monitoring accuracy of $0.01 \mathrm{~mm}$. Data were recorded every hour, with observations and warnings measured through the DRCEWP. Monitoring data were collected from January 2019 to July 2019 and December 2019 to April 2020 as shown in Figure 8. Although the horizontal positions of the 9 points 


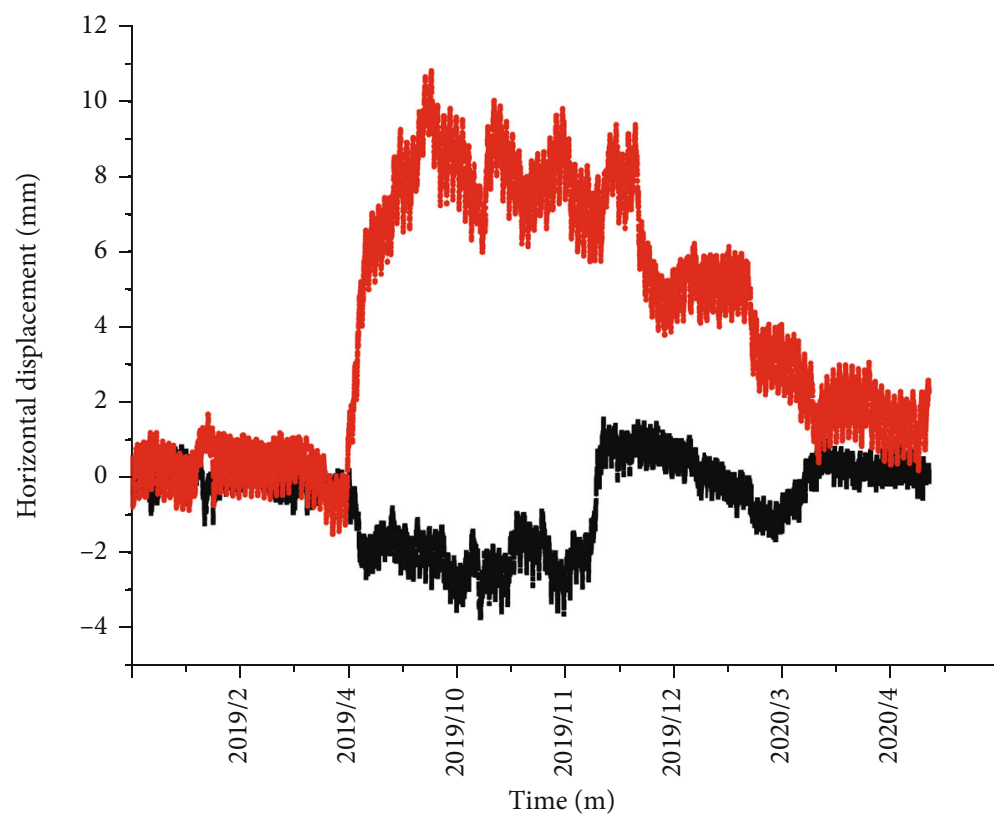

- South (-) North (+)

$\rightarrow$ East (+) West (-)

(a) Horizontal displacement of GPS-1 displacement monitoring point

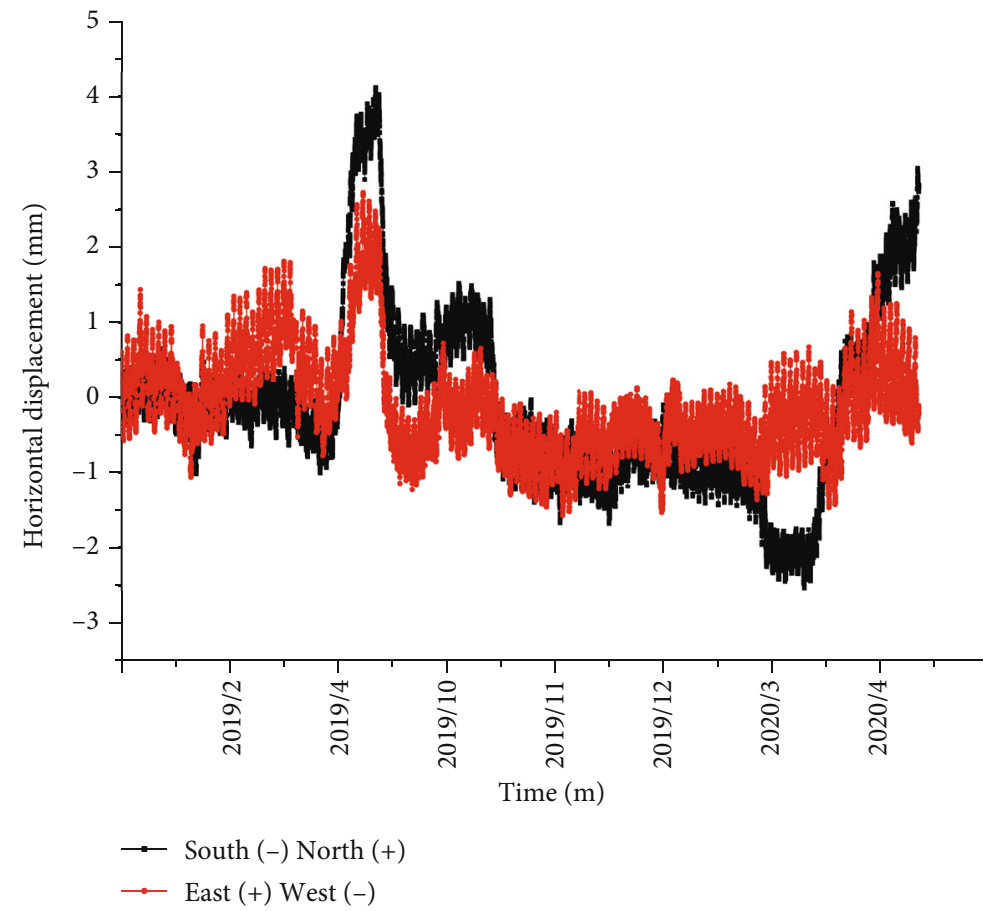

(b) Horizontal displacement of GPS-2 displacement monitoring point

Figure 10: Continued. 


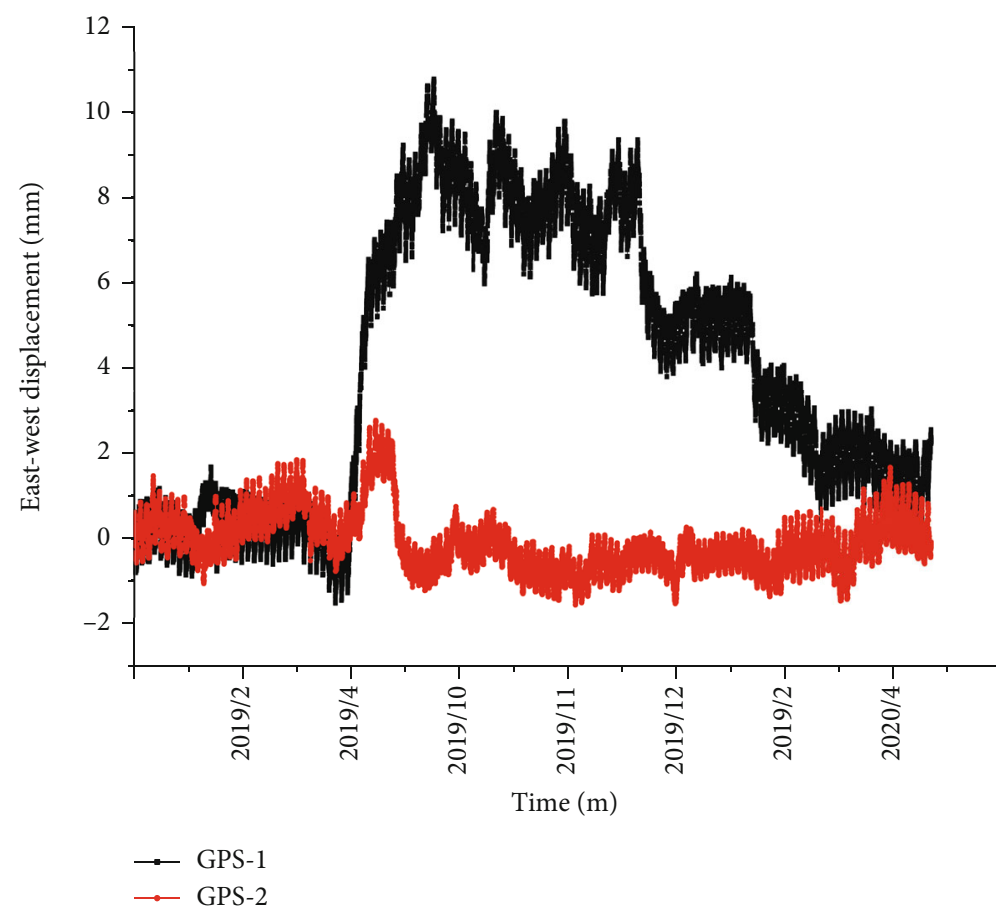

(c) Comparison of East-West Displacement of GPS1/GPS2 Monitoring Points

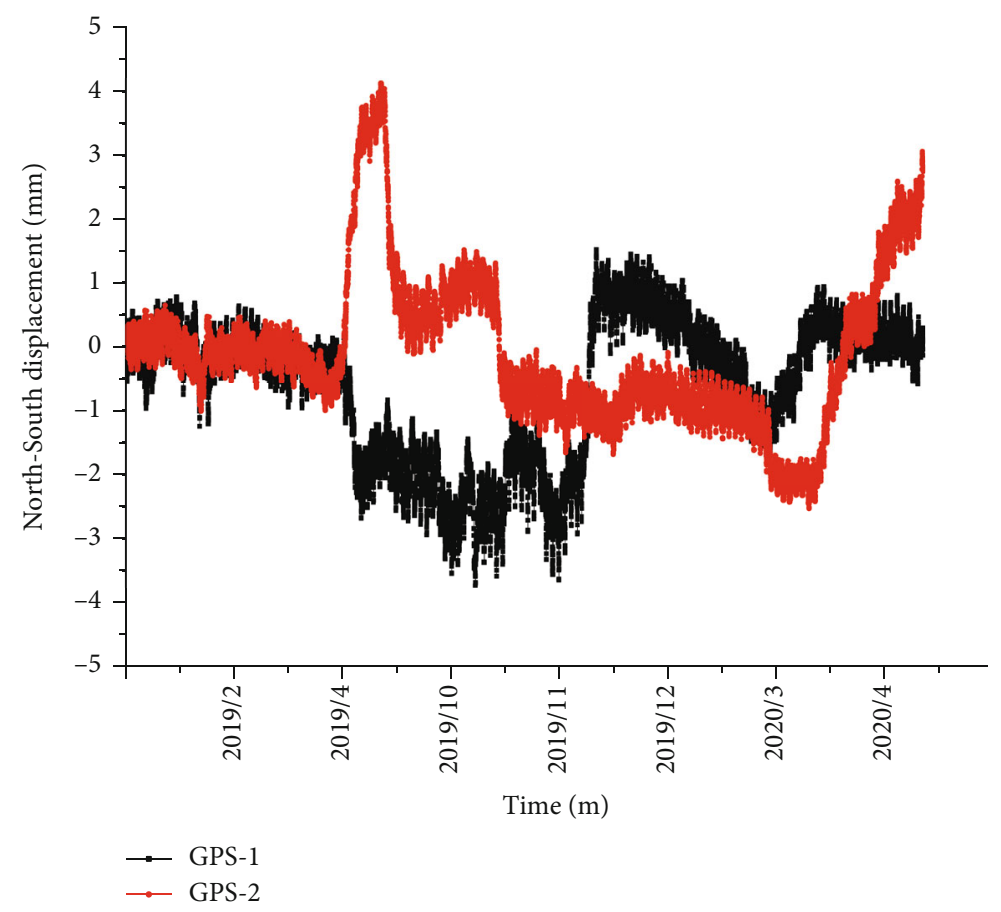

(d) Comparison of North-South Displacement of GPS1/GPS2 Monitoring Point

FIgURe 10: In situ monitoring data.

showed a unilateral decline over time, with an obvious settlement trend, the accumulated absolute values of deformation were relatively small, with the roof deformation trend requiring a longer period of observation.

5.2.3. Monitoring of the Ablation Rate. The laser monitoring data of the erosion rate in the cave were used for observations and early warning through the DRCEWP, with a monitoring accuracy of $0.05 \mathrm{~mm}$. Monitoring data were retrieved from November 2018 to January 2020 from 8 laser displacement sensors (Figure 9). The results showed that the distances of the 8 measuring points showed regular "expansion-contraction" alterations over time. The overall curve fluctuated in response to temperature changes, and the curvature changed as the seasons progressed. 
5.2.4. Cliff Deformation. Since the horizontal data of the GNSS monitoring points were more accurate than the vertical data, two horizontal monitoring data of the "SouthNorth" and "East-West" were selected for analysis. Comparing Figures 10(a) and 10(b) from 2019.4 to 2019.9 at the two monitoring points, the fluctuation range exceeded the normal range $( \pm 1 \mathrm{~mm})$, but the change in the No. 1 monitoring point was greater than that in No. 2. The maximum change in the East-West direction reached $10 \mathrm{~mm}$.

This phenomenon was due to strong wind and rain in the area on June $3^{\text {rd }}$, which caused a large tree with a diameter of $35-45 \mathrm{~cm}$ at the breast height, 5 meters from the corner of the cliff wall, to fall to the Northeast. The root rock mass was away from the No. 1 monitoring point, but No. 2 experienced displacement of the adjacent rock mass at the corner of the cliff, leading to variation in the values. The surrounding rock masses at the two monitoring points were cut by the fissures and were independent of each other. Both were in a state of "lap" and "occlusion." The structure was unstable, so a large displacement occurred under the action of the dynamic load (falling of the large tree). From the comparison of the EastWest displacement of the monitoring point in Figure 10(c), it can be seen that the accidental tree tipping caused the East-West displacement, which gradually recovered and stabilized.

In terms of the North-South displacement (Figure 10(d)), the monitoring curve also changed following tree tipping, but the amount of change was significantly smaller. On the other hand, and different from the East-West displacement, the North-South displacement has obvious fluctuation characteristics upon the arrival of the tourist season (such as the National Day), with a fluctuation range of between 3 and $5 \mathrm{~mm}$, as the tourists must gather and pass through the cliff leading to step passage damage. The structural stability of the grotto temple is not only related to external forces but also closely related to the immersion environment [38-40], which requires a longer monitoring period and more monitoring data to analyze. In addition, the anchor cable support structure with constant resistance and large deformation proposed by Tao et al. [41-42] also provides a method for the deformation control of the grotto temple rock wall, which will be an important research work in the future.

\section{Conclusion}

(1) Protection of the roof of the Yuanjue Cave is problematic due to large fluctuations in the inner surface, the narrow site, the numerous cultural relics in the work area, and the sensitivity to roof stress. A static roof support system can overcome the problem of layered installation. Key technical problems such as point-by-point lifting, static coupling, and monitoring equipment can ensure the safety and stability of the roof during the survey and design stage

(2) Deformation monitoring of the roof and surrounding rock mass showed the characteristics of complexity, multiple types, and high environmental tolerance requirements. The combination of the monitoring system and the preprotection system overcomes building issues in the Yuanjue Cave, providing a useful reference for similar unloading belt grotto protection monitoring

(3) Due to the age of excavation at the Yuanjue Cave Site, the impact of the excavation process and unloading on the surrounding rock of the cliff were stable. The deformation process of the rock mass surrounding the cliff wall of the Yuanjue Cave was prolonged and restricted by an array of factors

(4) Upon analysis, the deformation trend of the roof and surrounding rock mass of the Yuanjue Cave have been initially defined. However, a further work is required on the stability of the surrounding rock mass of the Yuanjue Cave, and more monitoring methods are required. Deformation monitoring and regular verification are required at various time points to provide technical support for the protection of the Yuanjue Cave

\section{Data Availability}

The data are available and explained in this article; readers can access the data supporting the conclusions of this study.

\section{Disclosure}

The manuscript was approved by all authors for publication.

\section{Conflicts of Interest}

The authors declare no conflict of interest.

\section{Acknowledgments}

This work was supported by the Dazu District Science and Technology Commission Project Funding (No. DZKJ, 2018ABB1011), the National Natural Science Foundation of China (41941018), and the Research and Development of Object-Oriented Photogrammetry by UAV (Unmanned Aerial Vehicle) and Rapid Deployment Monitoring and Early Warning Equipment on High-Steep Slope (2019YFC1509604).

\section{References}

[1] K. Z. Huang, "Thoughts on the protection of stone cultural relics," Chinese Cultural Heritage, vol. 86, no. 4, pp. 6-14, 2018.

[2] J. H. Wang and J. Q. Chen, "Analysis on the protection status and development of cave temples in my country," Southeast Culture, vol. 1, pp. 6-14+127-128, 2018.

[3] R. Zhang, "Analysis and research on the protection planning of Chinese cave temples," Chinese Cultural Heritage, vol. 4, pp. 49-60, 2018.

[4] D. J. Tong, "Protection and prospect of Dazu Rock Carvings," Science of Cultural Relics Conservation and Archaeology, vol. 3, pp. 57-60, 2003. 
[5] Y. C. Shi, "Genetic an alysis and countermeasures for main deseases of grottoe," Journal of Natural Disasters, vol. 1, pp. 106-112, 1997.

[6] C. Margottini, N. Antidze, J. Corominas et al., "Landslide hazard, monitoring and conservation strategy for the safeguard of Vardzia Byzantine monastery complex, Georgia," Landslides, vol. 12, no. 1, pp. 193-204, 2015.

[7] W. W. Chen, Z. Guo, J. Zhang et al., "Evaluation of long-term stability of Mogao Grottoes caves under enhanced loading conditions of tourists," Journal of Performance of Constructed Facilities, vol. 32, no. 4, article 04018048, 2018.

[8] X. Huang, S. Li, Z. Xu, M. Guo, and Y. Chen, "Assessment of a concealed karst cave's influence on karst tunnel stability: a case study of the Huaguoshan Tunnel, China," Sustainability, vol. 10, no. 7, article 2132, 2018.

[9] M. Geniş and B. Çolak, "Stability assessment of the Gökgöl Karstic Cave (Zonguldak, Turkey) by analytical and numerical methods," Rock Mechanics and Rock Engineering, vol. 48, no. 6, pp. 2383-2403, 2015.

[10] J. P. Chen, "Discussion on the preventive protection of Longmen Grottoes," Chinese Cultural Heritage, vol. 1, pp. 75-81, 2019.

[11] X. Li, "Preventive protection of grotto sites," History of Heilongjiang, vol. 5, p. 307, 2015.

[12] C. Y. Liu and M. C. He, "Study on the deformation failure mechanism and stability of ancient kings tomb:a case of national key cultural relic Gaogouli's Tai kings tomb," Journal of Earch Sciences and Environment, vol. 5, pp. 25-28, 2007.

[13] C. Y. Liu and M. C. He, "Field and laboratory measurements of the depth variations of mechanical properties and weathering degrees of rock structural components in anicent bridge," Journal of Engineering Geology, vol. 2, pp. 222-227, 2007.

[14] W. W. Zhan and G. J. Sun, "Study on the new reinforcement measure used for reinforcing folium on the top of grottoes," Dunhuang Research, vol. 6, pp. 21-25+121+127, 2009.

[15] E. C. Yan and Y. Fang, "Quantitative evaluation on the safety of the column rock masses in yungang grotto," Chinese Journal of Rock Mechanics and Engineering, vol. 23, Supplement 2, pp. 5046-5049, 2004.

[16] Z. X. Li, "Rock characteristics and reinforcement of the Silk Road grottoes," Dunhuang Studies, vol. 4, pp. 73-83+112$119,2002$.

[17] Y. He and L. Zy, "A study of geological disease analyses and renovation methods in Lingquan Temple Grotto of Henan, China," Rock and Soil Mechanics, vol. 1, p. 17, 2000.

[18] X. G. Wang, T. Peng, Y. Q. Guo et al., "Deformation causes of Longmen grottoes and control countermeasures," The Chinese Joumal of Ceological Hazard and Control, vol. 1, pp. 130-132, 2006.

[19] B. L. Gao, H. Y. Zhang, and Z. F. Yang, "Deformation causes of Longmen grottoes and control countermeasures," The Chinese Joumal of Ceological Hazard and Control, vol. 1, pp. 130-132, 2006.

[20] I. V. Brandi, M. R. Barbosa, R. G. De Paula, R. N. Araújo, R. S. de Moura, and H. M. de Lima, "Instrumented geotechnical monitoring of a natural cave in a near mine operation towards a sustainable approach to mining and preservation of speleological heritage," Journal of Cleaner Production, vol. 239, article 118040, 2019.
[21] Y. M. Zhang, Y. Luo, and X. W. Song, "Analysis report on the status quo of my country's world cultural heritage monitoring and early warning system," Chinese Cultural Heritage, vol. 6, pp. 29-34, 2018.

[22] Z. Jiewang, C. Zhonghua, L. Encong, Z. H. Luqing, and Y. A. Zhifa, "Failure causes and reinforcement countermeasures for no.1 grotto of longyou grottoes," Joumal of Engineering Geology, vol. 17, no. 1, pp. 126-132, 2009.

[23] Y. H. Jiang, J. H. Wang, L. B. Li et al., "Application and research on the stability monitoring system of grotto rock mass," Science of Cultural Relics Conservation and Archaeology, vol. 26, no. 4, pp. 70-75, 2014.

[24] D. Y. Wang, Z. X. Zhang, L. S. Fu, and Y. Jinshi, "Analyses of factors affecting destruction of rockmass by weathering in baodingshan grotto," Journal of Engineering Geology, vol. 2, pp. 54-65, 1994.

[25] C. Zhu, Z. Yan, Y. Lin, F. Xiong, and Z. Tao, "Design and Application of a Monitoring System for a Deep Railway Foundation Pit Project," IEEE Access, vol. 7, pp. 107591-107601, 2019.

[26] Q. Liu, J. Chai, S. Chen, D. Zhang, Q. Yuan, and S. Wang, "Monitoring and correction of the stress in an anchor bolt based on pulse pre-pumped Brillouin optical time domain analysis," Energy Science \& Engineering, vol. 8, no. 6, pp. 2011-2023, 2020.

[27] Z. Li, H. Liu, Z. Dun, L. Ren, and J. Fang, "Grouting effect on rock fracture using shear and seepage assessment," Construction and Building Materials, vol. 242, article 118131, 2020.

[28] Z. Li, S. Liu, W. Ren, J. Fang, Q. Zhu, and Z. Dun, "Multiscale laboratory study and numerical analysis of water-weakening effect on shale," Advances in Materials Science and Engineering, vol. 2020, Article ID 5263431, 14 pages, 2020.

[29] X. Yang, J. Wang, D. Hou, C. Zhu, and M. He, "Effect of drywet cycling on the mechanical properties of rocks: a laboratory-scale experimental study," Processes, vol. 6, no. 10, p. 199, 2018.

[30] W. Wang, L. Li, W. Xu, Q. X. Meng, and J. Lü, "Creep failure mode and criterion of Xiangjiaba sandstone," Journal of Central South University, vol. 19, no. 12, pp. 3572-3581, 2012.

[31] Q. X. Meng and W. Wang, "A novel closed-form solution for circular openings in generalized Hoek-Brown media," Mathematical Problems in Engineering, vol. 2014, Article ID 870835, 7 pages, 2014.

[32] Q. X. Meng, L. Yan, Y. L. Chen, and Q. Zhang, “Generation of numerical models of anisotropic columnar jointed rock mass using modified centroidal voronoi diagrams," Symmetry, vol. 10, no. 11, p. 618, 2018.

[33] Z. G. Tao, C. Zhu, X. B. Zheng et al., "Failure mechanisms of soft rock roadways in steeply inclined layered rock formations," Geomatics, Natural Hazards and Risk, vol. 9, no. 1, pp. 1186-1206, 2018.

[34] C. Zhu, M. C. He, M. Karakus, X. B. Cui, and G. Tao, "Investigating toppling failure mechanism of anti-dip layered slope due to excavation by physical modelling," Rock Mechanics and Rock Engineering, vol. 53, no. 11, pp. 5029-5050, 2020.

[35] W. R. Liu, J. K. Liu, and C. Zhu, "Multi-scale effect of acoustic emission characteristics of 3D rock damage," Arabian Journal of Geosciences, vol. 12, no. 22, p. 668, 2019.

[36] Q. X. Meng, H. L. Wang, W. Y. Xu, M. Cai, J. Xu, and Q. Zhang, "Multiscale strength reduction method for 
heterogeneous slope using hierarchical FEM/DEM modeling," Computers and Geotechnics, vol. 115, Article ID 103164, 2019.

[37] L. L. Yang, W. Y. Xu, Q. X. Meng, and R. B. Wang, "Investigation on jointed rock strength based on fractal theory," Journal of Central South University, vol. 24, no. 7, pp. 1619-1626, 2017.

[38] Q. Meng, H. Wang, M. Cai, W. Xu, X. Zhuang, and T. Rabczuk, "Three-dimensional mesoscale computational modeling of soil-rock mixtures with concave particles," Engineering Geology, vol. 277, article 105802, 2020.

[39] C. Zhu, X. D. Xu, W. R. Liu et al., "Softening Damage Analysis of Gypsum Rock With Water Immersion Time Based on Laboratory Experiment," IEEE Access, vol. 7, pp. 125575-125585, 2019.

[40] Q. Liu, S. Chen, S. Wang, J. Chai, and D. Zhang, "Experimental development process of a new cement and gypsum-cemented similar material considering the effect of moisture," Geofluids, vol. 2020, Article ID 8831801, 14 pages, 2020.

[41] Z. Tao, Z. Zhu, W. Han et al., "Static tension test and the finite element analysis of constant resistance and large deformation anchor cable," Advances in Mechanical Engineering, vol. 10, no. 12, Article ID 168781401881063, 2018.

[42] Y. Wang, B. Zhang, S. H. Gao, and C. H. Li, "Investigation on the effect of freeze-thaw on fracture mode classification in marble subjected to multi-level cyclic loads," Theoretical and Applied Fracture Mechanics, vol. 111, article 102847, 2021. 